\title{
John Hobson e a psicologia do jingoísmo: a metáfora da agulha hipodérmica e as origens da teoria crítica da propaganda
}

\section{Francisco Rüdiger}

\section{Resumo}

John Hobson concebeu estudo pioneiro do que viria a ser chamado de propaganda, em que, pela primeira vez, quem sabe, emprega a figura da agulha hipodérmica, não obstante a relativize criticamente, situando seus termos em relação à sua célebre teoria do imperialismo e a uma primitiva reflexão sobre as bases históricas da cultura de massas. Analisando como o autor desenvolve esse raciocínio em The Psychology of Jingoism (1901), revelamos no artigo a contribuição altamente original deste pioneiro aos estudos críticos de mídia. 0 argumento desenvolvido em conclusão é o de que, embora sua obra mostre que os meios exercem uma influência que depende do contexto histórico e das forças que nele intervêm, esta influência não tem um sentido inexorável, necessariamente favorável seja aos donos do poder e da imprensa, como demonstra, vista de forma distanciada, própria cobertura da Guerra dos Boers.

\section{Palavra-Chave}

Estudos críticos de comunicação: origens. John Hobson: The psychology of jingoism. História do pensamento comunicacional.
Francisco Rüdiger | frudiger@ig.com.br Doutor em Ciências Sociais pela Universidade de São Paulo (USP). Professor das Universidades Católica (PUCRS) e Federal do Rio Grande do Sul (UFRGS).

\section{Introdução}

John Hobson elaborou, no auge da era da imprensa, uma das primeiras análises críticas do que ainda viria a ser chamado de propaganda, situando-a em contexto intelectual que embora empregue, pela primeira vez, quem sabe, a figura da agulha hipodérmica, a relativiza criticamente, ao compor seus termos com uma teoria do imperialismo e os elementos de uma primitiva reflexão sobre as bases históricas e psicossociológicas da cultura de massas. Por volta de 1895, entraram os jornais em apoteose, chegando várias folhas a ter, nas metrópoles do capitalismo, tiragens diárias superiores a um milhão de exemplares. Houve uma reversão de entendimento sobre seu sentido e alcance em meios aos setores intelectualizados, fossem eles liberais ou socialistas: de meio formador da opinião, eles foram passando a ser vistos como eventuais instrumentos de sua manipulação.

De farol da opinião pública e/ou veículo de doutrinação partidária, a imprensa, com efeito, estava, segundo seus porta-vozes, se convertendo 
em expressão dos anseios, senão da vontade dos leitores. Os jornais começaram a ser vistos por aqueles como meio de expressão dos anseios e causas populares. De acordo com a teoria do espelho, processou-se uma reviravolta na maneira de se ver público. Os leitores passaram a ser cinicamente entendidos como mercado, a ser atendido por parte de um novo empresariado, que tomava nas mãos o cada vez mais próspero negócio jornalístico.

Dentro deste contexto, os periódicos, todavia, terminaram por se tornar, também, um fenômeno popular politicamente influente entre as massas, como sinaliza seu papel, por exemplo, no Caso Dreyfus e na Guerra Hispano-Americana (BRENNAN, 1988; CAMPBELL, 2003). Apareceu à consciência reflexiva liberal e socialista 0 fato alarmante da ressonância do novo jornalismo em vastas camadas sociais poder ser e de fato estar sendo explorada pelas forças políticas organizadas para fazer publicismo e obter apoio ideológico para seus diversos projetos, sobretudo em relação às ações do aparelho governamental.

Nosso objetivo, neste artigo, é expor a maneira como John Hobson submeteu todo este contexto a original estudo de caso em The Psychology of Jingoism (1901). Pioneiro no estudo do imperialismo, o autor lança mão, nesta obra, de uma análise histórica e sistemática que pode ser considerada modelo da pesquisa crítica de mídia que se desenvolveria ao longo do século XX. Embora examinando a psicologia de massas subjacente à Guerra dos Boers, 0 estudo revela como, em meio à sua expansão, a opinião pública passa por um processo de mudança diretamente conectado ao colapso do liberalismo, à ascensão das massas urbanas e à exploração da situação assim criada pelos poderes político e econômico, via a imprensa e outras agências de comunicação.

Depois de situar historicamente e de analisar as principais teses do texto em foco, 0 artigo discute seu significado como primeiro exercício de crítica ao que viria, mais tarde, ser chamado de propaganda. Valendo-se de seu ponto de vista privilegiado em termos epistêmicos e reflexivos, isto é, da distância em relação à época de proposição dessas teses, o relato procura tirar lições mais gerais do comentário de sua documentação. 0 argumento desenvolvido em conclusão é o de que, embora ela revele que os meios exercem uma influência que depende do contexto histórico e das forças que nele intervêm, esta influência não tem um sentido inexorável, necessariamente favorável seja aos donos do poder, seja aos donos da imprensa, como demonstra, sendo vista de forma mais abrangente, a própria cobertura da Guerra dos Boers.

\section{0 ocaso da era liberal e a ascensão do jornalismo de massas}

Durante as últimas décadas século XIX, a imprensa dos grandes centros mundiais passou por uma série de mudanças estruturais, que conduziram à conversão do público leitor em 
mercado das empresas jornalísticas surgidas em consonância com esta transformação. Nos Estados Unidos, Hearst e Pulitzer sinalizaram a renúncia ao jornalismo partidário e suas pretensões doutrinárias em relação à opinião pública, passando a defender que a imprensa deveria, antes, expressar seu pensamento. Para eles e seus acólitos, chegara a hora de os leitores encontrarem em seus veículos um porta-voz interessado em atender seus anseios, e nada mais. A conversão do impresso em bem de consumo de massa, vê-se, foi acompanhada do aparecimento de um discurso de atendimento do desejo do leitor, à revelia do que então podia pensar o público pensador de cultura.

Na Europa ocidental, não houve exceção, antes podemos encontrar outros casos paradigmáticos, como dá prova a situação no Reino Unido. A Revolução Industrial e a expansão urbana, mas sobretudo o Ato Educacional de 1870 fomentaram o surgimento de um público que passou a ser explorado pela imprensa. A abolição dos impostos que a gravavam e a crescente alfabetização da das massas criaram as condições institucionais para a popularização da leitura de livros, jornais e revistas.

A industrialização da imprensa, promovendo 0 aumento dos custos de publicação, levou à progressiva transferência de propriedade e controle da imprensa popular da classe trabalhadora para os ricos homens de negócio, enquanto a dependência da publicidade que assim se viabilizou encorajou a absorção ou eliminação da antiga imprensa radical, barrando seu desenvolvimento até a I Guerra Mundial (CURRAN; SEATON, 2006, p. 36).

De acordo com o liberalismo burguês oriundo do Século das Luzes, a sociedade civil, para seu bem, era e devia ser palco de um livre debate de ideias, baseado no emprego esclarecido da razão. Cada um podia e devia formar e expressar opinião sobre os assuntos de interesse geral. A opinião pública era a síntese desse processo, mediado pela ação doutrinária e o proselitismo intelectual da imprensa. 0 princípio que a estruturava ideologicamente era 0 da persuasão racional, apesar de ser sabido que os veículos formadores da opinião estavam sujeitos ao erro de julgamento e à eventual corrupção financeira (HABERMAS, 1984).

No final do século XIX, o panorama começou a se transformar, o individualismo liberal burguês passou a enfrentar a concorrência das doutrinas políticas e sociológicas de essência coletivista e cunho determinista. No Reino Unido, a crença no princípio da persuasão racional individual foi entrando em eclipse, diante das teorias que acusaram o condicionamento da opinião pela tradição (HAMPTON, 2001). Conforme se tornava um bem de consumo de massas, a reflexão prática sobre a imprensa foi, como dito, abandonando seu entendimento burguês e liberal como meio de esclarecimento das correntes de opinião pública. A comercialização levou "[...] os jornais a dar aos desprezados integrantes quase sem educação das classes trabalhadoras o que eles queriam" (HAMPTON, 2001, p. 220). 
Em consonância com várias reformas institucionais no capitalismo acontecia que o ponto de vista das camadas populares, que até então não era reconhecido como força relevante na condução dos assuntos públicos, estava passando a ser sentido nos centros de tomada de decisão e disputado pelas forças políticas melhor organizadas. Em perspectiva, estavam se formando as condições para 0 surgimento do fenômeno da propaganda, do emprego aberto ou camuflado dos meios de comunicação com o objetivo estratégico de obter apoio ideológico de vastos setores da população para uma causa ou organização, que se escancararia a partir da I Guerra Mundial.

Partindo da ideia de que a Guerra dos Boers foi produto de uma "conspiração armada pela imprensa" e de que, por essa via, "a consciência foi manipulada", Hobson (1900, p. 217, 228) desponta, numa primeira leitura, como um precursor de sua análise, interpelada sob a denominação tardia de teoria da agulha hipodérmica. 0 s termos empregados por ele, aliás, não dão margem à dúvida. Como afirma o autor, durante o conflito, 0 palanque, os púlpitos e os jornais "[...] injetaram [na consciência pública] noções e sentimentos que [...] induziram à formação de uma comunidade de pensamento, linguagem e ação até agora desconhecida" (HOBSON, 1901, p. 18, grifo nosso).

\section{Jingoísmo e a Guerra dos Boers}

Hobson nasceu em Derby, 1856, filho de um próspero proprietário de jornal, e faleceu em
Londres, como intelectual trabalhista, no ano de 1940 (TOWNSHED, 1990). Viveu na época em que 0 império britânico chegou a seu auge, despontando mundialmente como o primeiro em população, riqueza e poderio. Os extensos territórios que possuía em todos os continentes forneciam-lhe matérias primas baratas para suas indústrias e mercados consumidores cativos para os seus produtos manufaturados.

Oriundo de família burguesa, Hobson recebeu privilegiada educação política e formou-se em economia, área a que se dedicou como escritor independente. Engajado política e publicamente nas questões de seu tempo, militou na ala esquerda do partido liberal, transitando mais tarde para o partido trabalhista, em 1919. Ainda em 1900, elaborou sociologicamente 0 termo imperialismo para entender sua época e seu país, sendo em meio a seu estudo pioneiro sobre 0 tema que desenvolveu a análise do que era então chamado de jingoísmo.

Quando da Guerra entre a Rússia e o Império Otomano, em 1877/78, o cancioneiro popular inglês difundiu nos bares e music-halls do país uma peça de sucesso com forte apelo patriótico, em cujo refrão havia destaque para a expressão "Jingo". Significando "irei, por Jesus", era ela uma contração linguística e religiosa de cunho tradicional, que agora passava a ser cantada, com entusiasmo, por todos aqueles dispostos a conter o expansionismo russo e a defender pela guerra as prerrogativas do império britânico. Comentando 
0 fato pela imprensa, George Holyoake, oriundo dos meios intelectuais de esquerda, aproveitou a ocasião para cunhar o termo Jingoísmo, visando referir-se criticamente, de início, ao menos, às expressões populares e às ações políticas lastreadas no cultivo do nacionalismo radical que surgiam no Reino Unido.

Hobson (1900) propôs-se a elaborar teoricamente o conceito e a construir sua análise sistemática em plena época da Guerra dos Boers (18991902), cujo início acompanhou de perto, como correspondente local do Manchester Guardian. Como se sabe, o conflito provocou ampla repercussão internacional pelos jornais, sendo visto por muitos como um dos prenúncios da I Grande Guerra. Durante o século XIX, o expansionismo britânico levara à ocupação das antigas colônias holandesas no litoral sul-africano por parte de colonos ingleses. A migração dos holandeses radicados na região ("boers") para territórios mais ao norte, contudo, não impediu a escala das tensões entre as duas comunidades, complicadas ainda mais pela presença da população africana. Quando foram descobertas as ricas minas de ouro do Transvaal (1886), começou uma corrida para a região que o governo local, com o tempo, não teve como conter sem recorrer à força, levando à guerra dos estados boers com 0 Império Britânico.

Simultaneamente guerra romântica e antevisão da I Guerra Mundial, o conflito foi o primeiro a mobilizar uma opinião pública massiva em todo o mundo ocidental, e não apenas no Reino Unido. "A Guerra dos Boers teve considerável repercussão na arena internacional", escreve Wolfgang Mommsen. Em geral, o público internacional expressou maior simpatia pelos boers e, apesar do desdenho da diplomacia de seus governos pelos seus desejos e as pressões da imprensa, "a anglofobia chegou assim a novos picos" (MOMMSEN, 2001, p. 1-6; KUITENBROUWER, 2012).

Com razão, Stephen Badsey observa que 0 conflito foi uma guerra midiática, talvez a primeira. Graças ao emprego do telégrafo e o uso que lhe deram os serviços da agência Reuters, "[...] possuía-se comunicações que tornaram possível pela primeira vez reportar às metrópoles eventos de um teatro de guerra distante, com métodos outros do que os controlados pelos militares e o governo, e com velocidade 0 bastante para ter efeitos políticos diretos [na opinião pública]" (BADSEY, 1999, p. 75; MORGAN, 2002).

Objeto de extenso registro fotográfico, agora também aportado por amadores, graças aos avanços nas respectivas máquinas, 0 conflito forneceu vasto material para a nova imprensa ilustrada, na Europa e nos Estados Unidos. Na Inglaterra, porém, não ficou só nisso seu impacto, no tocante às repercussões cotidianas. Durante os momentos iniciais da Guerra, os heróis do país foram objeto de filmes, exibidos, para delírio dos frequentadores, nos pubs e music-halls. Os feitos militares foram cantados em versos e 
musicados em composições que se executava nos lares e em eventos sociais. A classe média baixa acompanhava as notícias como se parte de uma novela fossem, aproveitando os momentos de vitória para promover festas que ficaram marcadas na memória de Londres, como a da noite de (levantamento do sítio de) Mafeking (KREBS, 1999; THOMPSON, 2002).

Para entender a repercussão do evento na opinião pública mais ampla da época, é preciso levar em conta, porém, não tanto o fato dele, em meio à histeria patriótica britânica, ter ensejado também 0 conhecimento de intensas cenas de horror, como massacres, pilhagens, destruição sistemática de propriedades e, pela primeira vez, vastos internamentos dos inimigos em campos de concentração. Disso o público ocidental já tinha em parte noção, desde que fora revelada a calamitosa situação humanitária da população negra do Congo. 0 principal e mais chocante à sua consciência em relação à guerra foi mais a progressiva revelação de que estas atrocidades todas estavam sendo cometidas contra uma população branca, europeia e civilizada, sobretudo contra as mulheres e crianças boers, cujo morticínio nos campos de concentração teria chegado a 27 mil.

Hobson não chegou a tomar pleno conhecimento deste último dado durante a redação de sua obra, mas foi com preocupação pelos seus pressupostos e indignação pelas motivações de seu desencadeamento que a escreveu. Para ele, o escândalo maior da Guerra era ela ser o resultado menos de um objetivo estratégico da política imperial britânica do que da pressão popular sobre o governo arranjada pelas forças sociais com interesse econômico no sul da África, via o emprego do palanque, do púlpito e, sobretudo, da imprensa. Por isso, generalizou, "[...] o controle da imprensa pelos homens de negócio com 0 propósito de fazer negócios está na raiz de todo 0 jingoísmo" (HOBSON, 1901, p. 113).

De outro lado, acrescentou, 0 expansionismo baseado no emprego da força militar e as violências perpetradas no sul do continente africano por uma nação civilizada requerem uma explicação capaz de transcender os fatores exclusivamente econômicos. Os eventos revelam aspectos, senão uma tendência que só podem ser entendidos levando-se em conta a manipulação estratégica "[...] dos instintos primitivos da espécie humana" por parte do poderio econômico organizado, que, eventualmente "invocando a si uma missão civilizadora", logrou com aquela "[...]desviar a corrente de energia política dos problemas nacionais para 0 campo da política internacional", através da montagem de informações e da orquestração da opinião pública (HOBSON, [1902] 1981, p. 203).

No jingoísmo, os jornais, o púlpito e o palanque são, portanto, menos um fator de união ou de culto do poder nacional, do que meios ideológicos para aliviar as tensões sociais internas da nação, de acordo com os interesses dos setores econômicos 
imperialistas mais poderosos e organizados. Com ele, ainda se vai além, contudo, porque, assim, as três instituições sucumbem interesseiramente nos atavismos ancestrais que tensionam a existência das massas populares inclusive em meio à civilização, passando todas elas a dar sustentação à política de guerra imperialista das frações mais poderosas das classes dominantes.

\section{A Guerra e a fabricação da opinião}

Durante a era burguesa, relembremos, supunhase que a opinião pública, em última análise, se formava através do emprego da razão e do livre intercâmbio de ideias. Para Hobson (1901, p. 128), a Guerra dos Boers é sinal de uma nova época, de que, doravante, "a fabricação da opinião pública é possível e é alcançada". A consciência jingo é prova do colapso do princípio da racionalidade dos processos de formação da opinião na era das massas. 0 jingoísmo que a articula, em síntese, não é senão um dos vetores responsáveis por esse processo. No modo de ver do autor, o conflito com que ele mais de perto se associou está diretamente enredado na ação da imprensa desde 0 seu começo. 0 lobby em favor da intervenção militar contra os boers não ficou circunscrito às repartições públicas e corredores dos parlamentos, conforme costumava ser 0 caso no período anterior (MOMMSEN, 2001).

As tensões criadas pela corrida às minas de ouro dos territórios boers por parte dos colonos ingleses não podem ser separadas da sua exploração política e ideológica, via a imprensa e outras agências, por parte do imperialismo britânico. As empresas de mineração e transporte, apoiadas pela grande banca, lançaram uma campanha de apoio público à guerra, em nome da retaliação às ofensas cometidas contra os súditos ingleses pelos boers, conforme denunciadas pelos seus simpatizantes e agentes, dentro e fora do Parlamento.

Aparentemente, o governo britânico não desejava o conflito, nem a opinião pública se manifestava em seu favor. Porém, as forças nele interessadas formaram um grupo de pressão que, via a manipulação das informações por parte da imprensa austral, primeiro provocou a opinião pública, inventando relatos criminosos contra cidadãos ingleses e uma suposta ameaça boer à colônia do Cabo. Como nota Hobson (1901, p. 112), o público britânico foi informado sobre a situação local pela imprensa sul-africana, mantida pela banca e as empresas de transporte e mineração, que assim conseguiram satisfazer seu "[...] desejo de controlar a opinião pública".

Depois, Alfred Milner, principal autoridade inglesa na região, trabalhou em favor da adesão da opinião pública britânica à solução militar, respaldando, na colônia e na metrópole, as denúncias da imprensa do Cabo e sua Igreja (HOBSON, 1901, p. 22-24). Enfim, Cecil Rhodes, principal liderança do setor imperialista, logrou com seu grupo obter 0 apoio dos principais jornais da oposição e da imprensa eclesiástica para pressionar o governo, 
fazendo cessar os escrúpulos de consciência por parte do público e das autoridades com relação a levar o país à guerra no sul da África (HOBSON, 1900, p. 219).

Quando a esta união da imprensa somaram-se as vozes vindas de milhares de púlpitos $\mathrm{e}$ a instrução vinda de milhares de palanques, onde viajantes, missionários, políticos e filantropos empregaram substancialmente 0 mesmo conjunto de fatos e dele extraíram a mesma moral, a posição em favor da guerra foi selada (HOBSON, 1901, p. 109)..

Na África do Sul britânica, aprofunda o autor, os principais jornais eram controlados pelos setores imperialistas, a começar pelos editados pela Argus Company. Nos estados boers, também, as folhas em inglês estavam a soldo dos mesmos setores. Por sua vez, "[...] o salão de bar, o clube social, o trem e outras vias de comunicação ajudaram [o noticiário da imprensa] a fazer o trabalho de propaganda [na áfrica do Sul]" (HOBSON, 1901, p. 117). Os serviços telegráficos, enfim, fizeram 0 resto, visto que a maior parte dos jornais ingleses, de início, tinha poucos repórteres na região e difícil acesso àqueles serviços. Quando não era 0 caso, note-se, eles trabalhavam para redações de veículos cujas empresas eram controladas pelos interesses imperialistas, como exemplifica o caso do The Times.

No Reino Unido, segue 0 autor, a campanha de opinião pública foi ainda mais ampla e organizada.
A Associação da África do Sul britânica coordenou e promoveu várias ações, desde comícios e palestras, até a publicação de livros e a agitação nos pubs e music-halls. A polícia reprimiu as manifestações dos contrários à guerra e não impediu que se os atacassem nas ruas e nos domicílios. Houve censura aos setores pró-boers e demorou a se romper a unanimidade da imprensa. Agitadores foram comissionados para percorrer o país, visando manter um clima de opinião favorável à guerra. Assim, porém, o jingoísmo "[...] penetrou em todas as partes das conversas privadas, no vagão de trem, no salão de chá, na sala de estar e, às vezes, até mesmo na publicidade do music-hall" (HOBSON, 1901, p. 40).

Hobson (1900, p. 206) menospreza em sua análise o papel da nova imprensa popular, exponenciada pelo Daily Mail (fundado em 1896), partindo do suposto de que "[...] não é preciso assumir que, para promover a guerra, ela é organizada por interesses externos: em geral, bastam para tanto apenas seus próprios interesses comerciais". ${ }^{1}$ Quando se obtém 0 controle da grande imprensa, escreve, "0 interesse próprio do jornalismo amarelo faz o resto" (HOBSON, 1901, p. 116). Em contrapartida, o autor salienta o papel desempenhado em todo este processo de condução da opinião pública pela Igreja Anglicana. Para ele, ela se concertou com os interesses imperialistas, "abençoando" a Guerra pelos púlpitos e seus materiais impressos. 
0 pensador recorre mais de uma vez à metáfora

da seringa hipodérmica em seu estudo, afirmando,

por exemplo, que os setores imperialistas

asseguraram "0 controle de todas as vias de

inteligência importantes" e, com base nisso, "[...]

as usaram para injetar na consciência pública

uma corrente contínua de falsa ou distorcida de

informação". Quem examina o caso todo, postula 0 autor para o leitor britânico, concluirá que "[...] foi sua influência e evidências que, em última análise, nos forçaram à guerra" (HOBSON, 1901, p. 138). A política imperialista e sua ação militar foram sem dúvida responsabilidade "[...] da extraordinária concordância entre as imprensas local e metropolitana, a secular e a religiosa, a liberal e a unionista na apresentação dos principais fatos, no diagnóstico da situação e na sua pressão em favor de uma política de força" (HOBSON, 1901, p. 108).

Para 0 autor, o jingoísmo é promovido no plano da consciência muito mais do que no da ação e, como tal, consiste sobretudo em um movimento especulativo, virtualmente criado pela imprensa e demais instituições mencionadas. Porém, não é algo meramente inventado, precisando ser entendido antes como uma síndrome ideológica que nasce das condições de vida modernas. A consciência jingo é em parte fabricada pelos setores que controlam ou comandam as instituições formadoras da opinião, em parte uma expressão latente ou reação espontânea às circunstância criadas com 0 avanço do imperialismo, conforme concluiu o autor com base em sua leitura de Marx mas, também, da obra de Gustave Le Bon ([1895] 1922).

\section{A psicologia do jingoísmo}

John Hobson (1901, p. 5) baseou nas ideias dos autores para entender criticamente o jingoísmo como produto da exploração ideológica de uma síndrome psicossocial, oriunda das condições de vida modernas, por parte das forças políticas imperialistas, através das instituições formadoras da consciência coletiva no Reino Unido. Nesse sentido, a consciência jingo, o patriotismo infantil desprovido de saber e imaginação, se caracterizaria, segundo o exame do autor, pelos seguintes traços:

1. Credulidade ideológica - o jingoísta é o sujeito a quem falta o senso crítico diante da realidade política de seu país, que não sabe fazer uso da razão, que ignora a necessidade de se argumentar com base em evidencias, em vez das paixões, e deseja acreditar nos discursos preparados para consumo de massas.

\section{Barbarismo sádico - o jingoísta está} disposto a comprar sensações que satisfaçam seus desejos reprimidos, predisposto a ser "provocado e manipulado em relação aos brutais anseios de domínio permanentemente latentes na humanidade civilizada" (HOBSON, [1902] 1981, p. 211).

\section{Imediatismo intelectual - o jingoísta} prefere seguir a onda geral, absorvendo detalhes soltos e desconexos, sensacionais, 
em vez de refletir a longo prazo e com fundamento em alguma doutrina.

\section{Embotamento espiritual - o jingoista é 0} sujeito que se deixa tomar pela raiva contra o outro e, assim, leva seu humor ao eclipse, porque tem embotadas suas faculdades mentais da imaginação: seu espírito "é uma fúria cega" (HOBSON, 1901, p. 78).

\section{Cinismo moral - o jingoísta, ainda} que confusamente, sabe que a política imperialista que pretende enaltecer as virtudes de sua nação de fato também sustenta os interesses econômicos particulares dos setores sociais mais poderosos.

\section{Fatalismo histórico - o jingoísta é 0} sujeito em que a corrupção da inteligência tem seu ponto culminante, sendo o caso, com a postulação de que as realidades humanas são como são, todos os povos têm um destino previamente determinado.

Em síntese, Hobson (1901, p. 9; [1902] 1981, p. 204-205) ainda salienta que o jingoísmo é, essencialmente, um movimento psicológico, uma paixão especular, não prática, que tem menos a ver com 0 anseio selvagem de participar de uma luta do que com a satisfação espiritual de uma imaginação neurotizada pelas condições de vida na época do imperialismo. 0 militarismo imperial que ele apoia, em geral, só satisfaz vicariamente
0 instinto de perseguição existente entre seus sujeitos. Por isso, resumindo, o jingoísmo tem a ver, sobretudo, com o desfrute estético e emocional das aventuras do imperialismo, não há nele bem 0 exercício de poder do homem de ação, mas antes "[...] a voluptuosidade do espectador [objetivamente distanciado]" (HOBSON, [1902] 1981, p. 205).

Levando em conta estes aspectos, fica mais fácil entender porque, para 0 autor, 0 extremismo nacionalista que o jingoísmo encarna é uma forma de canalizar as energias liberadas pelas tensões internas, que resultam da exploração do trabalho e da contenção do bem-estar social trazidos pela produção industrial moderna, para 0 confronto com um inimigo externo.

As forças financeiras e industriais do império, utilizando os partidos políticos, a imprensa, a igreja e o sistema educativo, moldam a opinião pública e a política, mediante a idealização das sendas primitivas que empurram o homem à luta, a dominar os outros e a acumular riquezas, tendências que sobrevivem em meio aos muitos anos de paz e ordem surgidos com a era industrial (HOBSON, [1902] 1981, p. 210).

Para ele, o jingoísmo é, em última instância, promovido, mas não criado pela imprensa e outros aparatos, porque não se sustenta por conta própria: ele remete a uma forma de consciência cujas raízes estão antes na forma como se desenvolve a sociedade capitalista ao ingressar no estágio do imperialismo. Quem ignora tal circunstância, não compreenderá como e porque "o sentimento público da Grã-Bretanha acabou 
sendo manipulado de acordo com os interesses dos que simplesmente calculavam os lucros que teriam com a guerra" (1901, p. 91).

\section{LeBon ([1895] 1922) elaborou uma variante} organicista da concepção idealista da história cujo principal problema, nos parece, não está em ter visto a ascensão das massas ao proscênio da vida social, mas sim em jamais ter conseguido explicar as origens deste processo, em esclarecer porque, na era moderna, as crenças definham e as opiniões se volatizam, como, bem ou mal, conseguiu fazer, por exemplo, Georg Simmel. Hobson, como este último, enfrentou esta questão, mas, em vez de remetê-la sociologicamente à figura da economia monetária, a exemplo de Simmel, propôs como solução seu entendimento como efeito ou momento do desenvolvimento do capitalismo industrial. Para ele, o jingoísmo é a versão britânica da mobilização dos instintos primitivos da população por parte das classes dirigentes e dos estamentos intelectuais que as apoiam, com vista à criação do suporte ideológico interno necessário à condução da política do capitalismo imperialista (HOBSON, [1902] 1981, p. 191).

Nesse sentido, seria um equívoco, afirma o autor, reduza o jingoísmo "[...] à influência hipnótica de certas palavras sobre a mente da multidão" (1901, p. 98). 0 jingoísmo não é um simples movimento imposto de cima para baixo, baseado em motivos inventados artificialmente pelos seus promotores. Os políticos e empresários imperialistas não 0 criaram de forma consciente e deliberada, para "pôr o público inglês a favor de seus interesses". Em essência, o fenômeno tem a ver com "[...] a apropriação instintiva de todos os sentimentos e ideias vigorosas que podem ajudá-los", via a sua elaboração, promoção e difusão entre a população, com vistas ao seu emprego com os mais diversos objetivos e projetos (HOBSON, [1902] 1981, p. 191).

Conforme explica nosso autor, o fenômeno possui um lastro histórico objetivo, que remete às circunstâncias de desenvolvimento do capitalismo industrial (HOBSON [1894] 1984). A acumulação do capital é um processo que acaba por esbarrar nos limites do estado nacional, seja pela falta de matérias primas, pelo subsconsumo resultante da exploração da mão de obra e/ou pela crescente resistência a tanto por parte do movimento dos trabalhadores. 0 capitalismo industrial moderno, nas condições de um mundo desigualmente desenvolvido, necessariamente conduz, portanto, à formação de impérios coloniais. 0 resultado é uma competição fortemente militarizada pela conquista de mercados e fontes de matérias primas, que submete as relações internacionais a permanente instabilidade, e as nações ao risco da Guerra Mundial, como será o caso da que rebentará em 1914.

Resultado da evolução do capitalismo industrial moderno, o jingoísmo como ideologia é a forma com que as massas se iludem a respeito de seu papel na sociedade e destino na história da 
civilização nas condições que aquele processo desenvolve no Reino Unido (HOBSON, [1902] 1981, p. 198). As condições da vida moderna que ele produz levam à formação de massas urbanas e, de acordo com isso, ao surgimento de novos tipos de consciência. As rápidas, variadas e numerosas mutações na estrutura da vida civilizada favorecem 0 "[...] enfraquecimento da resposta individual na formação das opiniões e, por esta via, ao correspondente aumento da suscetibilidade ao jingoísmo" (HOBSON, 1901, p. 14). A consciência predisposta a acolher 0 jingoísmo, efeito deste processo, com efeito, não é senão a consciência sujeita à sugestão e ao contágio de imagens, ansiosa por consumir sensações e desejosa de encontrar descarga em entretenimento violento.

Em resumo, o jingoísmo é, portanto, "manipulação da consciência pública” (p. 107-108), conforme essa consciência "[...] é modificada e intensificada por certas condições da moderna civilização" (p. 2). Como tal, representa a apropriação ideológica e exploração política e estética dos instintos ancestrais, como o ódio pelo estrangeiro, e das crenças irracionais, como os sentimentos patrióticos populares, pelas forças políticas e econômicas organizadas em meio à época do imperialismo. 0 fenômeno pouco tem de propriamente primitivo: em essência, é ele produto das comunidades civilizadas, "[...] por mais que extraia nutrientes de sobrevivências da natureza selvagem" (p. 12).
Em Hobson, o jingoísmo não é, pois, uma aberração ideológica, que emergiria da ressurreição dos instintos primitivos entre as massas, como pretende Price (1977). 0 fenômeno é a psicologia ou forma de consciência com que os setores hegemônicos e seus apoiadores intelectuais, "mediante o controle da imprensa, dos centros docentes e, quando preciso, das igrejas, impõem o imperialismo às massas, disfarçando-o como patriotismo exaltado". Como tal, seria, portanto, menos um movimento político de massas do que o efeito, neste último contexto, de "uma técnica de manejo da nação [britânica]" (HOBSON, [1902] 1981, p. 325). Em última análise, seu sentido é criar respaldo público para a intervenção do estado em favor dos grandes interesses econômicos e desviar a atenção dos problemas internos e dirigir o espírito de revolta contra a má distribuição da riqueza e as dificuldades econômicas para o mundo exterior.

\section{Conclusão}

John Hobson concluiu sua análise do jingoísmo antes do conflito entre boers e ingleses chegar a seu termo, não tendo podido incluir em seu texto muitos elementos que, talvez, poderiam ter conferido outros rumos à sua abordagem das conexões entre o fenômeno e as agências de formação da consciência então existentes. Os piores barbarismos cometidos pelos ingleses recém principiavam a ser abertamente revelados em toda a sua extensão no momento de lançamento do livro. Ainda em 1901, porém, os 
jornais começaram já a balancear a cobertura do conflito no sul da África. A reprodução, de mais e mais fotografias dos internos nos campos de concentração, revelou ao público britânico os horrores da guerra e seu desrespeito de suas forças armadas aos princípios mais elementares do humanitarismo. Junto com os terríveis relatos sobre a situação das mulheres e crianças internadas nos campos, publicados na imprensa pela enfermeira Emily Hobhouse, elas tiveram imenso e devastador impacto na consciência pública da época, sobretudo entre os setores femininos da população e em todo o mundo ocidental (KREBS, 1999).

Combinados com os gigantescos gastos com a guerra, os recrutamentos em massa e o elevado número de mortos e feridos dos soldados, em boa parte pela falta de condições de higiene, estes fatos foram, via a imprensa, "[...] promovendo uma visão cada vez mais negativa e carregada de culpa em relação à antes gloriosa guerra do sul da África" (MORGAN, 2002, p. 12).

Por fim, quando surgiu a notícia de que os cidadãos britânicos, cujos interesses tinha sido o principal motivo usado pela imprensa para levar o país à guerra, estavam sendo preteridos por collies chineses, mantidos em condições de semiescravidão, nas minas daquela parte do mundo, a bolha de euforia murchou completamente. Os conservadores foram, não só por isso, é claro, retirados do poder e, em seu lugar, eleitos líderes que tinham mantido reservas ou mesmo haviam se oposto à guerra, condenando-se à derrota nas urnas muitos dos jingoístas radicais (1906).

Hobson (1901, p. 124), note-se, até cogitou esta situação, escrevendo, no final de seu livro, que "[...] a confiança pública investida pela paixão [por parte dos jornais] demora a cair, mas uma vez se instalando a desconfiança, chegará 0 dia em que 0 crédito da imprensa se arruinará fatalmente". Entretanto, não pensou que esta desconfiança poderia se originar da própria atividade jornalística e que, em vez desta última, seu principal alvo seriam, momentaneamente, ao menos, os setores mais imperialistas do Governo Britânico.

Destarte, a Guerra do Boers ensina que, como 0 púlpito e o palanque em tempos mais remotos, a imprensa organizada como empresa, de fato foi e, talvez, ainda seja um poder em nossa sociedade, mas este não é instrumentalizável ideologicamente o tempo todo e numa única direção pelos seus controladores diretos ou indiretos, nem possui um sentido ontológico necessariamente de cima para baixo, sempre favorecendo os setores politicamente mais poderosos na estrutura social.

Assim como na França a imprensa, após ter servido aos setores chauvinistas, acabou ajudando a levar os grupos republicanos radicais ao poder, denunciando a manipulação da opinião por parte dos círculos conservadores durante 0 Caso Dreyfus, a cobertura jornalística 
da guerra sul-africana, planejada para servir aos setores mais radicais do imperialismo inglês, no final das contas, contribuiu não apenas para revelar-lhe as manobras, mas, ainda, para fazer avançar o humanitarismo e as forças pacifistas no império britânico (THOMPSON, 2002; BADSEY, 1999).

Falando de modo mais amplo, conclui-se, por isso, que os meios têm donos, mas estes últimos manejam com força que, no principal, não controlam, porque suas fontes, embora provenham, cada vez mais, da interação de sujeitos sociais atomizados, nas condições de uma economia de mercado desenvolvida estes se revelam cada vez mais capazes de revisar e expressar suas preferências, graças às próprias circunstâncias que fazem depender os meios daquela economia. Em termos típicos e havendo inteligência, o que melhor se pode fazer com eles é explorar situações de oferta e procura, porque o poder da imprensa, em vez de ser expressão ou instrumento, é antes o de uma mediação da vida social que se estrutura de acordo com os mecanismos de mercado.

Em última análise, portanto, o poder da imprensa deveria ser visto como função do fetichismo da mercadoria que impera de forma cada vez mais abstrata entre os seres humanos - algo que, contudo, só começaria a ficar mais claro bom tempo depois da época dos fatos que aqui relatamos só passaria a ser teorizada à época da morte de John Hobson (1940).

\section{Referências}

BADSEY, Stephen. War correspondents in the Boer War. In: G00CH, John (Org.). Boer War - direction, experience and image. Londres: Frank Cass, 2000. p. 187-202.

BADSEY, Stephen. The Boer war as a media war. In: DENNIS, Peter; GREY, Jeffrey (Org.). The Boer War - army, nation and empire. Camberra: AHU, 1999. p. 70-83.

BRENNAN, James. The reflections of the Dreyfuss affair in the European press. Nova York: Lang, 1988.

CAMPBELL, Joseph. Yellow journalism. Westport: Greenwood, 2003.

CURRAN, James; SEATON, Jean. Power without responsibility. 6.ed. Londres: Routledge, 2003.

HAMPTON, Mark. Understanding media: theories of the press in Britain, 1850-1914. Media, Culture \& Society, Londres, v. 23, n. 2, p. 213-231, mar. 2001.

HABERMAS, Jürgen. Mudança estrutural da esfera pública. Rio de Janeiro: Tempo Brasileiro, 1984.

HOBSON, John. Democracy after war. Londres: Allen \& Unwin, 1917.

The crisis of liberalism. Londres: King \& Son, 1909.

Estudio del imperialismo. Madri: Alianza, [1902] 1981.

The psychology of jingoism. Londres: Grant Richards, 1901.

The war in South Africa. Londres: Loader Nisbet, 1900.

KREBS, Paula. Genre, race and the writing of empire. Cambridge: Cambridge University, 1999.

KUITENBROUWER, Vincent. War of words: Dutch pro-boer propaganda and the South African war. Amsterdam: Amsterdam University Press, 2012. 
LE BON, Gustave. Psychologia das multidões. Rio de Janeiro: Garnier, [1895] 1922.

MOMMSEN, Wolfgang. Introduction. In: KEITH, Wilson (Org.) The International impact of Boer War. Nova York: Palgrave, 2001. p. 1-7.

MORGAN, Kenneth. The Boer War and the media. Twentieth century British history, 0xford, v. 13, n. 1, p. 1-16, janeiro 2002.

PENNY, Summerfield. Patriotism and empire: musichall entertainment. In: MACKENZIE, John (Org.). Imperialism and popular culture. Manchester: Manchester University, 1986. p. 17-48.

PRICE, Richard. Society, status and jingoism. In: CROSSICK, Geoffrey (Org). The lower-middle class in Britain. Londres: Helm, 1977. p. 89-113.

RICHARDS, Thomas. Commodity culture of Victorian England. Stanford: Stanford University, 1990.

THOMPSON, Andrew. Publicity, philanthropy and commemoration. In: OMISSI, David; THOMPSON, Andrew (Org.). The impact of the South African War. Nova York: Palgrave, 2002. p. 99-123.

TOWNSHED, Jules. J. H. Hobson. Manchester: Manchester University, 1990. 


\section{John Hobbes and the psychology of jingoism: the metaphor of the hypodermic needle and the origins of critical propaganda}

\section{Abstract}

During the heyday of the press age, John Hobson drafted one of the first critical analyzes of what would be called propaganda, inside which, equally as a pioneer, he employed the figure of the hypodermic needle to understand the phenomena. Composing its terms with a theory of imperialism and the elements of an early reflection on the historical basis of mass culture, he nevertheless could mitigate this schema. Analyzing how the author develops those ideas in The Psychology of jingoism (1901), the article revealed the highly original contribution to the study of the media offered by this forerunner of the critical approach. The argument developed in conclusion is that, although his work shows that the media exert an influence that depends on the historical context and the forces involved in it, this influence does not have an inexorable sense necessarily in favor of those in power, to be owners of the press, as shown, being seen in a broader historical view, the same coverage of the Boer War, the case studied by Hobson.

\section{Keywords}

Critical communication studies: historical roots.

John Hobson: The psychology of jingoism. History of communicative thinking.

\section{John Hobson y la psicologia del jingoísmo: la metáfora de la aguja hipodérmica y los orígenes de la teoría crítica de la propaganda}

\section{Resumen}

John Hobson ha redactado, en el auge de la era de la prensa, una de las primeras criticas de lo que vendría a llamarse propaganda. En el contexto de esta crítica empleo, también de forma pionera, la metáfora de la aguja hipodérmica, comedida por su teoría del imperialismo y la reflexión por el esbozada sobre las bases históricas y psicológicas de la naciente cultura de masas. Mediante análisis de la manera como el autor desarrolla este argumento en La psicología de lo jingoísmo (1901), el artículo revela la contribución muy original al estudio de los medios propuesta por este primeiro crítico de los medios. El argumento desarrollado en conclusión es que, a pesar de que su trabajo demuestra que los medios de comunicación ejercen una influencia que depende del contexto histórico y de las fuerzas que intervienen en ella, esta influencia no tiene que ser siempre favorable a aquellos en el poder, 0 para los dueños de la prensa, como muestra, vista en una perspectiva histórica más amplia, la propia cobertura de la guerra de Boer, el caso estudiado por Hobson.

\section{Palabras-clave}

Estudios críticos de la comunicación. John Hobson: The psychology of jingoism. História de lo pensamiento comunicacional. 


\section{Expediente}

A revista E-Compós é a publicação científica em formato eletrônico da Associação Nacional dos Programas de Pós-Graduação em Comunicação (Compós). Lançada em 2004, tem como principal finalidade difundir a produção acadêmica de pesquisadores da área de Comunicação, inseridos em instituições do Brasil e do exterior.
E-COMPÓS I www.e-compos.org.br I E-ISSN 1808-2599

Revista da Associação Nacional dos Programas de Pós-Graduação em Comunicação.

E-compós, Brasília, v.16, n.1, jan./abr. 2013

A identificação das edições, a partir de 2008 ,

passa a ser volume anual com três números.

\section{CONSELHO EDITORIAL}

Afonso Albuquerque, Universidade Federal Fluminense, Brasil Alberto Carlos Augusto Klein, Universidade Estadual de Londrina, Brasil Álvaro Larangeira, Universidade Tuiuti do Paraná, Brasil André Luiz Martins Lemos, Universidade Federal da Bahia, Brasil Ângela Freire Prysthon, Universidade Federal de Pernambuco, Brasil Angela Cristina Salgueiro Marques, Faculdade Cásper Líbero (São Paulo), Brasil Antonio Roberto Chiachiri Filho, Faculdade Cásper Líbero, Brasil Arthur Autran Franco de Sá Neto, Universidade Federal de São Carlos, Brasil Benjamim Picado, Universidade Federal Fluminense, Brasil César Geraldo Guimarães, Universidade Federal de Minas Gerais, Brasil Cristiane Freitas Gutfreind, Pontifícia Universidade Católica do Rio Grande do Sul, Brasil

Denilson Lopes, Universidade Federal do Rio de Janeiro, Brasil Eduardo Peñuela Cañizal, Universidade Paulista, Brasil

Eduardo Vicente, Universidade de São Paulo, Brasil Eneus Trindade, Universidade de São Paulo, Brasil Erick Felinto de Oliveira, Universidade do Estado do Rio de Janeiro, Brasil Florence Dravet, Universidade Católica de Brasília, Brasil Gelson Santana, Universidade Anhembi/Morumbi, Brasil Gislene da Silva, Universidade Federal de Santa Catarina, Brasil Guillermo Orozco Gómez, Universidad de Guadalajara Gustavo Daudt Fischer, Universidade do Vale do Rio dos Sinos, Brasil Hector Ospina, Universidad de Manizales, Colômbia Herom Vargas, Universidade Municipal de São Caetano do Sul, Brasil Inês Vitorino, Universidade Federal do Ceará, Brasil Jay David Bolter, Georgia Institute of Technology Jeder Silveira Janotti Junior, Universidade Federal de Pernambuco, Brasil John DH Downing, University of Texas at Austin, Estados Unidos José Afonso da Silva Junior, Universidade Federal de Pernambuco, Brasil José Carlos Rodrigues, Pontifícia Universidade Católica do Rio de Janeiro, Brasil José Luiz Aidar Prado, Pontifícia Universidade Católica de São Paulo, Brasil Kelly Cristina de Souza Prudêncio, Universidade Federal do Paraná, Brasil.
Laan Mendes Barros, Universidade Metodista de São Paulo, Brasil Lance Strate, Fordham University, USA, Estados Unidos Lorraine Leu, University of Bristol, Grã-Bretanha Lucia Leão, Pontifícia Universidade Católica de São Paulo, Brasil Malena Segura Contrera, Universidade Paulista, Brasil

Márcio de Vasconcellos Serelle, Pontifícia Universidade Católica de Minas Gerais, Brasil

Maria Aparecida Baccega, Universidade de São Paulo e Escola Superior de Propaganda e Marketing, Brasil

Maria Ataide Malcher, Universidade Federal do Pará, Brasil

Maria das Graças Pinto Coelho, Universidade Federal do Rio Grande do Norte, Brasi Maria Immacolata Vassallo de Lopes, Universidade de São Paulo, Brasil Maria Luiza Martins de Mendonça, Universidade Federal de Goiás, Brasil Mauro de Souza Ventura, Universidade Estadual Paulista, Brasil Mauro Pereira Porto, Tulane University, Estados Unidos Mirna Feitoza Pereira, Universidade Federal do Amazonas, Brasil Nilda Aparecida Jacks, Universidade Federal do Rio Grande do Sul, Brasil Osvando J. de Morais, Universidade de Sorocaba, Brasil Potiguara Mendes Silveira Jr, Universidade Federal de Juiz de Fora, Brasil Renato Cordeiro Gomes, Pontifícia Universidade Católica do Rio de Janeiro, Brasil Robert K Logan, University of Toronto, Canadá

Ronaldo George Helal, Universidade do Estado do Rio de Janeiro, Brasil Rose Melo Rocha, Escola Superior de Propaganda e Marketing, Brasil Rossana Reguillo, Instituto de Estudos Superiores do Ocidente, Mexico Rousiley Celi Moreira Maia, Universidade Federal de Minas Gerais, Brasil Sebastião Guilherme Albano da Costa, Universidade Federal do Rio Grande do Norte, Brasil

Simone Maria Andrade Pereira de Sá, Universidade Federal Fluminense, Brasil Tiago Quiroga Fausto Neto, Universidade de Brasília, Brasil Suzete Venturelli, Universidade de Brasília, Brasil Valerio Fuenzalida Fernández, Puc-Chile, Chile

Veneza Mayora Ronsini, Universidade Federal de Santa Maria, Brasil Vera Regina Veiga França, Universidade Federal de Minas Gerais, Brasil

\section{COMISSÃO EDITORIAL}

Adriana Braga I Pontifícia Universidade Católica do Rio de Janeiro, Brasil

Felipe Costa Trotta I Universidade Federal Fluminense, Brasil

CONSULTORES AD HOC

Bruno Campanella, Universidade Federal Fluminense, Brasil

Christa Berger, Universidade do Vale do Rio dos Sinos, Brasil

Edison Gastaldo, Universidade Federal Rural do Rio de Janeiro, Brasil

José Luiz Braga, Universidade do Vale do Rio dos Sinos, Brasil

\section{EDIÇÃO DE TEXTO E RESUMOS I Susane Barros}

SECRETÁRIA EXECUTIVA I Juliana Depiné

EDITORACã̃ ELETRÔNICA I Roka Estúdio
COMPÓS I www.compos.org.br

Associação Nacional dos Programas de Pós-Graduação em Comunicação

Presidente

Julio Pinto

Pontifícia Universidade Católica de Minas Gerais, Brasil juliopinto@pucminas.br

Vice-presidente

Itania Maria Mota Gomes

Universidade Federal da Bahia, Brasil

itania@ufba.br

Secretária-Geral

Inês Vitorino

Universidade Federal do Ceará, Brasil

inesvic@gmail.com 